\title{
Reflexões sobre a aluação da Advocacia-Geral da União em projetos de geração de energia hidrelétrica $^{7}$
}

Tania Patricia de Lara Vaz

\section{Introdução}

Em todos os Ministérios que compõem o governo federal brasileiro, há Consultorias Jurídicas, órgãos de execução da Advocacia-Geral da União (AGU)², cujos advogados de carreira participam, diuturnamente, do processo complexo de formulação e implementação de políticas públicas, dos estudos, discussões, tratativas e negociações para o desenvolvimento de programas e projetos de governo, de valor estratégico para o crescimento do país. O presente artigo tem por escopo a investigação dessa atuação e do papel que desempenham os advogados de Estado, com abordagem a partir da administração pública e dos resultados e impactos previstos para as políticas públicas. A discussão que se propõe é sobre a efetividade da atuação da AGU na concepção e execução de programas e projetos do governo federal, partindo-se da etapa de modelagem das concessões para construção de usinas hidrelétricas. 
A implantação de usinas hidrelétricas não foi escolhida por acaso. Dada a importância estratégica da hidroeletricidade para o desenvolvimento econômico e social brasileiro, a participação da AGU no desenvolvimento de tais projetos ganha relevo. O Plano Decenal de Expansão de Energia (PDE-2019) evidencia, com efeito, que a geração de eletricidade terá fonte prevalente em usinas hidrelétricas, no percentual significativo de $69,85 \%$. As hidrelétricas, portanto, são imprescindíveis para a expansão da capacidade energética, planejando-se aumento de $40 \%$ da capacidade instalada até $2019^{3}$. Em outras palavras, sob o enfoque da gestão pública e dos movimentos de modernização do Estado, a partir da década de 1980, principalmente - as denominadas reformas gerenciais -, pretende-se trazer luzes sobre a atuação dos órgãos de consultoria e assessoramento jurídico da AGU. No tocante ao processo de modernização e reforma do Estado, alude-se, mais especificamente, às iniciativas, em nível mundial, notadamente nos países ocidentais de orientação capitalista (com destaque para a União Europeia e OCDE - Organização para Cooperação e Desenvolvimento Econômico), de reformulação dos paradigmas burocráticos na administração pública, em prol de maior eficiência, eficácia e efetividade da atuação governamental e foco nos resultados das políticas públicas. A gestão por resultados, nesse sentido, prioriza os impactos visados pelo governo para determinado projeto ou programa, para além da atenção a aspectos formais e procedimentais. Todo um conjunto de novas ideias deriva desta diretriz inicial, entre elas, o planejamento e o alinhamento estratégicos, a orientar decisões governamentais, como a alocação de recursos e a capacitação de servidores públicos; a criação de indicadores de avaliação da eficiência, da eficácia e da efetividade, entre outros.

Como se disse, para a reflexão proposta, elege-se a área de geração de energia elétrica, mais especificamente a outorga de concessão para aproveitamento de potenciais hidráulicos, com foco na etapa inicial de modelagem do leilão, nos termos da Lei $n^{\circ}$ 9.427, de 1996, com a redação dada pela Lei $n^{\circ} 10.848$, de 2004, que instituiu o novo modelo do setor elétrico, conforme se verá adiante. É nesse campo, em particular, que se pretende examinar a atividade jurídica de consultoria e assessoramento prestada pela advocacia pública, sobretudo no âmbito do próprio Ministério de Minas e Energia, e as transformações pelas quais passa, sob o influxo dos movimentos reformistas e de tendências como a New Public Management (Nova Gestão Pública), a New Public Service e a Governance.

O que se propõe, em última análise, é investigar se a atuação consultiva e de assessoramento jurídico da AGU desenvolve-se com atenção aos objetivos, impactos e resultados das políticas desenvolvidas pelo governo federal, para além da análise de aspectos formais, como a competência, a forma dos atos, procedimentos e requisitos legais, na linha e sob o influxo dos movimentos e tendências de reforma e modernização do Estado, inserida que está a instituição no contexto da administração pública, em sentido amplo.

\section{O estudo da atuação da AGU sob o enfoque da gestão pública}

O marco da reforma gerencial da administração pública federal, no Brasil, é o Plano Diretor da Reforma do Aparelho do Estado (PDRAE), de 1995, proposto e coordenado pelo então Titular do Ministério da Administração Federal e da Reforma 
do Estado (Mare), Luiz Carlos Bresser-Pereira. O PDRAE não se implementou como previsto; independentemente disso, contém diretrizes inspiradas em reformas gerenciais que se desenvolviam, sobretudo nos países da OCDE e da União Europeia (UE). A administração pública gerencial é orientada predominantemente pelos valores da eficiência e da qualidade na prestação de serviços públicos e pelo desenvolvimento de uma cultura gerencial nas organizações (CostA, 2008).

Breve contextualização é oportuna, na exposição do cenário político, administrativo, social e econômico que ensejou a reformulação do Estado do Bem-estar Social, ou Estado Providência, no qual se insere a reforma gerencial brasileira. Ainda que cada nação tivesse situação e circunstâncias particulares e específicas, decorrência natural do sistema político adotado, do estágio social e econômico, da história e do modelo de administração pública, é fato que, de modo geral, o modelo do Estado do Bem-estar Social passou a ser largamente questionado. A partir do final da década de 1970, sobretudo, surge a noção de falha governamental. Até então, reconheciase apenas a falha do mercado, que exigia a regulação, principalmente por meio da propriedade estatal e intervenção direta do Estado na economia. O consenso sobre o papel provedor do Estado como produtor direto de bens e serviços começou a sofrer forte crítica (MAJONE, 1999). A globalização econômica passou a pressionar os Estados para que se tornassem mais eficientes, na medida em que a indústria e o mercado nacional precisavam ser mais competitivos em nível ultranacional. Também os parceiros internacionais passam a exigir, crescentemente, maior eficiência dos órgãos nacionais que atuam em nível global. Além disso, o bom preparo das autorida- des para representar seus respectivos Estados em nível global - em termos de expertise, credibilidade e capacidade de execução - gera maior capacidade de influenciar as mudanças nos processos de decisão supranacionais e internacionais, o que é esperado pelos cidadãos e setores econômicos de cada nação. Paralelamente, o custo e o peso orçamentário do Estado provedor tornam-se insustentáveis, bem assim a intervenção direta estatal no

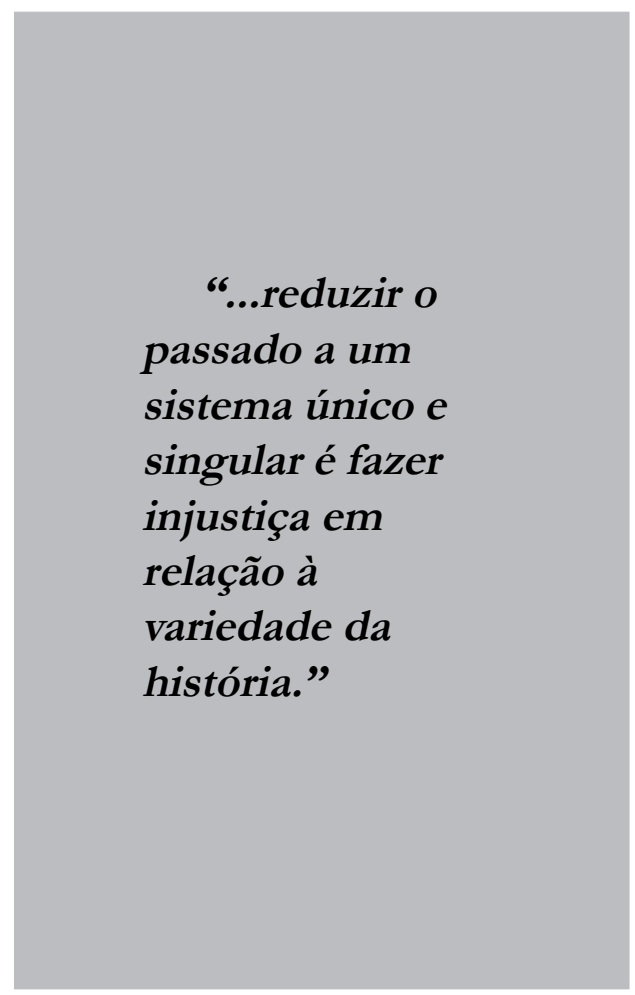

domínio econômico e social. Por outro lado, havia disfuncionalidades internas, como a impossibilidade incontestável de abrangência total no tocante à redistribuição social equitativa e às políticas de redução das incertezas sociais e econômicas, chegando-se ao limite do comprometimento da competitividade da economia nacional com sobrecarga fiscal e aumento das despesas públicas. As circunstâncias, 
sucintamente expostas, levam à reformulação do Estado Providência e de sua burocracia.

No Brasil, particularmente, a transição democrática gerava a fragmentação da capacidade decisória do governo, demandando processos de decisão politicamente negociados, mais abertos e participativos, que esbarravam na estrutura autocrática do Estado. Mergulhada nessa crise, havia uma agenda a pressionar o Estado: de um lado, um forte movimento em favor do desmonte, desburocratização, descentralização e desestatização, em parte por imposições financeiras; de outro, a reafirmação pelo poder constituinte da força do Estado como superinstituição, com previsão de muitas e novas competências, inclusive no tocante à infraestrutura (CostA, 2008).

A noção de administração pública, constituída por um corpo técnico profissional, com estrutura hierárquica, procedimentos administrativos e competências definidas, com função primordial de cumprimento da lei, surge no século XIX e foi a base para a estruturação do Estado Providência. Com efeito, não seria possível ao Estado assumir crescentemente atividades, serviços sociais e funções, sem a existência desse corpo técnico especializado, que os desempenhasse. Pollit e Bouckaert elencam o que designam por características do modelo burocrático: "[...] esferas fixas de competências, uma hierarquia definida de setores; uma clara distinção entre os papéis público e privado (e a propriedade que caracteriza este último); especialização e competência como base para a ação; corpo de servidores de carreira dedicado em tempo integral ao serviço público"; e "gestão pela aplicação de um conjunto de regras procedimentais, voltadas ao desenvolvimento dos trabalhos, conhecimento esse que consubstancia as competências técnicas específicas a cargo do corpo administrativo" (Pollit; Bouckaert, 2004, tradução própria) ${ }^{4}$, afastando o equívoco da superação do "modelo burocrático" na afirmação de que não existiu somente um tipo de regime administrativo, mas vários, e que reduzir o passado a um sistema único e singular é fazer injustiça em relação à variedade da história.

Nessa linha, o modelo burocrático cumpriu e ainda cumpre seu papel, segundo registro de Peters:

O sistema tradicional de administração pública persistiu por décadas e, de modo geral, foi extremamente bem-sucedido. Enfrentou várias guerras mundiais, produziu e administrou a massiva expansão de programas sociais, instituiu a gestão econômica em larga escala para o setor público e deu início a um grande número de políticas extraordinárias. Este sistema, contudo, foi do orgulho ao desamparo (G. Dows and Larkey, 1986). O que gerou a crítica largamente difundida à governança pública ocorrida durante os anos 80 e $90 ?$ ?" (Peters, 1996, tradução própria)

Assim, ainda que haja um grupo de críticos da burocracia, que propõem sua supressão, sobretudo o designado grupo dos reinventors, nos Estados Unidos, é fato que os políticos sempre reconhecerão que a eliminação da burocracia irá limitar diretamente o poder de ação do Estado e as políticas que suporta. A França, por exemplo, aumentou o tamanho de seu corpo administrativo em 25\% nos últimos 15 anos (Suleiman, 2003). Em sistemas políticos centralizados, como Reino Unido e França, o papel da burocracia de estabelecer e man- 
ter o poder estatal é reconhecido (Pollit; Bouckaert, 2004). Além disso, a burocracia $^{6}$ é vista como ator legítimo do Estado, concluindo os dois autores com um veredito final:

Em suma, a burocracia continuará a florescer no século XXI pelas mesmas razões em que se desenvolveu no século passado, por facilitar o processo de governança de maneira que outros modelos de organização não o fazem. Desafios à burocracia irão sempre ser desafios marginais, com a transferência de tarefas e atividades do setor público para o setor privado, por exemplo. Debaixo destas respostas cosméticas propostas pelas reformas, entretanto, ainda se vê que a burocracia weberiana continua a definir uma pluralidade de atividades, encargos e responsabilidades (MeIER; Hill, 2005, tradução própria $)^{7}$.

Em síntese, a burocracia é uma forma de organização social que, particularmente desenvolvida na administração pública, traduz-se como meio para realizar, eficientemente, os propósitos políticos do governo dada a racionalidade que a orienta, sob a égide da legalidade, e tendo em conta as dimensões do Estado Moderno. O objetivo da burocracia, em última análise, é a eficiência. O que se vê, porém, é que nem sempre as organizações burocráticas são eficientes. Essa é uma das razões pelas quais os paradigmas burocráticos vêm sendo questionados, principalmente a partir dos anos 1980. Robert Merton (1968) fala em "disfunção", para referir-se à consequência que se interpõe ao ajustamento, criando problemas na estrutura. Merton e Selznick, que constituíram o núcleo fundador da teoria organizacional de base sociológica nos Estados Unidos a partir dos anos 1940, analisaram casos de radicalização e descontextualização dos objetivos e procedimentos burocráticos, que passam a ser objetivos em si, independentemente de sua finalidade, gerando altos níveis de ineficácia organizacional (VAsconcelos, 2004). A expressão "disfunção burocrática", portanto, referese a problemas resultantes do funcionamento da organização burocrática.

Sem dúvida, o excesso de formalismo na formulação e aplicação da lei pode ser estudado sob o viés da disfunção burocrática $^{8}$. A advocacia de Estado insere-se na organização burocrática estatal responsável pela formulação e implementação de políticas públicas e programas de governo. É sob esse enfoque que a atuação de consultoria e assessoramento jurídico será estudada. Com efeito, o corpo administrativo (a burocracia, nesse sentido) é responsável pela execução de programas e projetos governamentais. Na medida em que é instrumento de efetivação de políticas públicas definidas pelo governo, a excessiva "neutralidade técnica" desse corpo pode levar à desconexão da atuação administrativa em relação aos propósitos políticos e legítimos em jogo. A propósito, Merton aborda especificamente o que refere como "devoção a regras":

“[...] inadequações na orientação que envolvem incapacidade claramente derivam de fontes estruturais. O processo pode ser brevemente recapitulado. (1) Uma burocracia eficaz exige confiabilidade de resposta e devoção estrita às regras. (2) Tal devoção com as regras transforma-as em absolutas, deixam de ser concebidas relativamente a um específico conjunto de finalidades. (3) Isto interfere na pronta adaptação 
de tais regras em condições especiais não previstas claramente por aqueles que elaboraram as regras gerais. (4) Assim, os próprios elementos que conduzem à eficiência, em geral, produzem ineficiência em casos específicos. A plena realização da inadequação raramente é atingida por membros do grupo que não se divorciaram dos significados que as regras têm para eles. Essas regras tornam-se simbólicas, ao invés de estritamente utilitárias." (Merton, 1968, tradução própria).

De outra maneira, é o que expõe Salis Gomes, fazendo referência ao trabalho de Derlien:

A importância conferida a partir da ideia do Estado liberal à legalidade das condutas, 'criando uma teoria das formas jurídicas esvaziada de conteúdo e alheia aos fins da actividade administrativa', contribuiu para que o Estado, excluída qualquer interacção com a sociedade civil (Monnier), olhasse menos para o resultado das políticas públicas do que para o travejamento jurídico da sua actividade: 'pensar em termos de programas (com objectivos definidos e projectos para os atingir) está fora do horizonte de quem se habituou a considerar as leis em princípio feitas para a eternidade [...]' (Derlien, 1990 apud Gomes, 1998).

Valendo-se do reforço de Rui Machete (1991), Salis Gomes expõe que a administração pública portuguesa é exemplo da supremacia da legalidade, em detrimento dos resultados das políticas públicas, na medida em que o foco está no ato administrativo (tem papel central e é o veículo normal do poder público). A ação é organizada por processos que terminam em atos administrativos, e não diretamente em função de resultados econômicos, sociais ou outros (GOMES, 1998) ${ }^{10}$.

\section{Novo modelo do setor elétrico, UHE Jirau e a atuação da Consultoria Jurídica}

Após uma década de reformas no setor elétrico, a expectativa de expansão da oferta com ganhos de qualidade na prestação dos serviços de fornecimento, segurança de suprimento e redução tarifária não se concretizaram (CORREIA et al., 2006). A partir de 2003, no primeiro mandato do presidente Luiz Inácio Lula da Silva, constatando-se os excessos da postura pró-mercado, a débil capacidade de ampliação da oferta exclusivamente por meio da liberalização e as lições aprendidas com a crise energética de 2001, iniciaram-se estudos no sentido da implementação de um modelo com bases mais firmes em regulação e intervenção estatal e com retomada do planejamento centralizado da expansão do sistema. Em março de 2004, por meio das Leis $\mathrm{n}^{\text {os }} 10.847$ e 10.848 , e seus respectivos decretos, inaugurou-se novo modelo para o setor elétrico, focado na maximização da segurança do suprimento de energia elétrica; na eficiência econômica, expressa pelo princípio da modicidade tarifária; e pela universalização do acesso. No tocante ao primeiro aspecto, priorizaram-se a suspensão da privatização das geradoras, de modo a concentrar os recursos disponíveis na expansão da oferta; o estímulo à criação de um mercado de contratos de longo prazo; a criação do Comitê de Monitoramento de Setor Elétrico (CMSE), para acompanhamento das condições de oferta e demanda do sistema; a exigência prévia de licenças ambientais para 
permitir a participação de um novo empreendimento no processo de licitação (evitando-se futuras complicações legais e atrasos nas obras); e a retomada do planejamento setorial integrado e centralizado pelo Estado, com a criação da Empresa de Pesquisa Energética (EPE). O CMSE tem a função de acompanhar e avaliar permanentemente a continuidade e a segurança do suprimento eletroenergético em todo o território nacional. A EPE, por sua vez, vinculada ao Ministério de Minas e Energia, tem por finalidade prestar serviços na área de estudos e pesquisas destinadas a subsidiar o planejamento do setor energético.

De modo a implementar tarifas módicas, foi prevista a compra de energia elétrica por meio de leilões públicos, também em relação à energia nova, reduzindo o risco de financiamento de obras de novos empreendimentos. Diferenciando-se os leilões para aquisição de energia de empreendimentos existentes e leilões de energia de novos empreendimentos, pretende-se reduzir significativamente o risco de investimentos dos geradores, que iniciam o empreendimento com fluxo garantido de receitas e com capacidade de viabilizar financiamento mais barato, pela vinculação dos recebíveis como garantia junto às instituições financeiras (CORREIA et al., 2006). Registre-se essa significativa modificação da sistemática da concessão de uso de bem público, em relação ao modelo anterior a 2004. Com efeito, passaram a se realizar leilões de compra de energia elétrica, sagrando-se vencedor o proponente que oferte lance com o menor valor de tarifa pelo serviço de energia (art. $15 \mathrm{da}$ Lei $n^{\circ} 8.987$, de 1995, com a alteração promovida pela Lei no 9.648, de 1998). Antes disso, o critério primordial dos leilões era a melhor oferta pelo valor da concessão. $\mathrm{E}$ finalmente, visando à ampliação do acesso, o governo federal instituiu o Programa Luz para Todos. No novo modelo, o mercado de energia elétrica é dividido em dois ambientes: Ambiente de Contratação Regulada (ACR), voltado para consumidores cativos; e Ambiente de Contratação Livre (ACL), para consumidores livres. Foram excluídas do Programa Nacional de Desestatização as empresas estatais de geração, transmissão e distribuição, cuja alienação estava prevista na Lei n ${ }^{\circ}$ 9.648, de $1998^{11}$. Além disso, o Mercado Ataca-

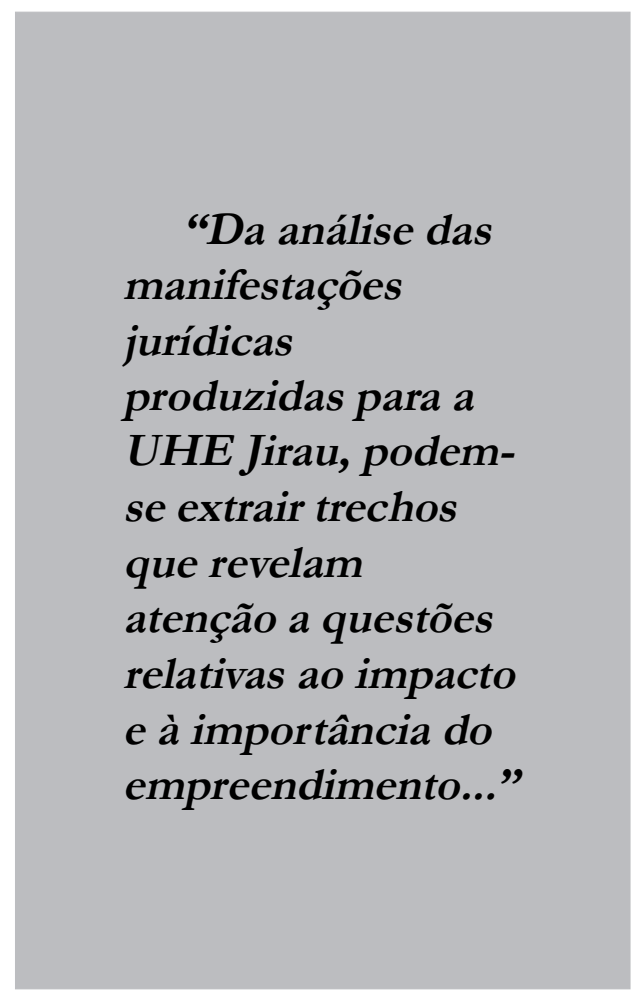

dista de Energia Elétrica (MAE) foi substituído pela Câmara de Comercialização de Energia Elétrica (CCEE). O atual modelo institucional incorpora a existência de um período de transição, com o gradual desenvolvimento de um mercado desregulado e crescimento da participação dos investidores privados na atividade de geração. A despeito dos preços do mercado 
regulado estarem reconhecidamente baixos, cresce o interesse no mercado livre, refletindo ganhos de competitividade dentro da atividade de geração e entre produtores e distribuidores. A expansão do mercado livre, sem dúvida, evidencia que a queda no preço da energia é resultado de instituições mais sólidas, instrumentos regulatórios mais claros e uma conjuntura favorável de excesso de energia. Há necessidade de alguns ajustes, relacionados à definição mais clara das competências regulatórias das diferentes agências reguladoras e a lacunas nas legislações que tratam de gás natural e sistemas isolados; e ainda existem conflitos de competência entre diferentes órgãos e entidades da administração direta e indireta (CORREIA et al., 2006).

Relativamente aos novos empreendimentos de geração e aos contratos de concessão de energia elétrica, situação da UHE Jirau, registra-se que o novo modelo prevê o seguinte: os contratos de concessão não poderão mais ser prorrogados, indefinidamente, enquanto os serviços estiverem sendo prestados nas condições estabelecidas no instrumento e de acordo com a legislação em vigor; compete ao poder concedente, ou seja, à União, elaborar o plano de outorgas, definir as diretrizes para os procedimentos licitatórios e promover as licitações destinadas à contratação de concessionários de serviço público para produção, transmissão e distribuição de energia elétrica e para a outorga de concessão para aproveitamento de potenciais hidráulicos, com delegação à Agência $\mathrm{Na}$ cional de Energia Elétrica (Aneel) para operacionalização dos procedimentos licitatórios respectivos; compete também ao poder concedente celebrar os contratos de concessão ou de permissão de serviços públicos de energia elétrica, de concessão de uso de bem público e expedir atos autorizativos, facultando-se delegação à Aneel; a contratação regulada, mediante licitação, será formalizada por meio de contratos bilaterais denominados Contrato de Comercialização de Energia no Ambiente Regulado (CCEAR); para a energia elétrica proveniente de novos empreendimentos de geração, tais contratos bilaterais poderão prever entrega com início no $3^{\circ}$ ou no $5^{\circ}$ ano após a licitação e prazo de suprimento de no mínimo 15 e no máximo 35 anos; as concessões de geração de energia elétrica, contratadas a partir da Medida Provisória n ${ }^{\circ}$ 144, de 11 de dezembro de 2003, terão o prazo necessário à amortização dos investimentos, limitado a 35 anos, contado da data da assinatura do imprescindível contrato; no processo de licitação pública de geração, as instalações de transmissão de uso exclusivo das usinas a serem licitadas devem ser consideradas como parte dos projetos de geração, não podendo os seus custos serem cobertos pela tarifa de transmissão; no edital de licitação para novos empreendimentos de geração elétrica, poderá constar percentual mínimo de energia elétrica a ser destinada ao mercado regulado, podendo a energia remanescente ser destinada ao consumo próprio ou à comercialização para contratação livre ${ }^{12}$; cabe ao Conselho Nacional de Política Energética (CNPE) sugerir a adoção de medidas necessárias para garantir o atendimento à demanda nacional de energia elétrica, considerando o planejamento de longo, médio e curto prazos, podendo indicar empreendimentos que devam ter prioridade de licitação e implantação, tendo em vista seu caráter estratégico e de interesse público, de forma que tais projetos venham assegurar a otimização do binômio modicidade tarifária e confiabilidade do Sistema Elétrico. Por outro lado, não houve mu- 
dança em relação à previsão de concessão, mediante licitação, do aproveitamento de potenciais hidráulicos de potência superior a $1.000 \mathrm{~kW}$, destinado à execução de serviço público, nos termos da Lei no 9.074 , de 7 de julho de 1995, que estabelece normas para outorga e prorrogações das concessões e permissões de serviços públicos.

A definição das diretrizes e sistemáticas para o leilão de contratação de concessionária para construção da Usina Hidrelétrica de Jirau, que integra o Complexo do Rio Madeira, no Estado de Rondônia, é da competência do Ministério de Minas e Energia (MME), poder concedente, nos termos da Lei n ${ }^{\circ}$ 9.427, de 1996 (art. 3º), com a redação dada pela Lei $n^{\circ} 10.848$, de 2004. Trata-se de projeto estruturante, com prioridade na licitação e implantação. A modelagem do leilão de compra de energia elétrica, com outorga da concessão de uso de bem público, para aproveitamento hidráulico, foi inteiramente concebida pelo MME dentro das regras do novo modelo do setor elétrico. Por delegação do Ministério, à Agência Nacional de Energia Elétrica coube promover o procedimento licitatório, de acordo com as diretrizes emanadas do Ministério de Minas e Energia.

Assim, por meio da Portaria $n^{\circ} 36$, de 12 de fevereiro de 2008, o ministro de Minas e Energia aprovou as diretrizes para o Leilão de Compra de Energia Elétrica proveniente da Usina Hidrelétrica Jirau, publicado no Diário Oficial da União de 13/02/2008, cuja minuta foi submetida formalmente à apreciação da Consultoria Jurídica do Ministério de Minas e Energia, que exarou a Nota Conjur/MME no 37/ 2008, por encaminhamento da Assessoria Econômica. Também a minuta da Resolução $\mathrm{n}^{\circ} 1$, de 11 de fevereiro de 2008, do CNPE, cujo presidente é o ministro de Minas e Energia, publicada no Diário Ofi- cial da União de 15/02/2008, que indica o Aproveitamento Hidrelétrico de Jirau como projeto de geração com prioridade de licitação e implantação e define pontos obrigatórios para o edital de leilão, foi objeto de apreciação formal pela referida Consultoria Jurídica (Parecer Conjur/ MME $\left.n^{\circ} 44 / 2008\right)$. E, ainda, a minuta da Portaria $n^{\circ} 114$, de 20 de março de 2008, do MME, publicada no Diário Oficial da União de 24/03/2008, que aprovou a sistemática para o leilão em exame, nos termos do seu Anexo, objeto de Nota Conjur/ MME; e a minuta do decreto que outorga à empresa Energia Sustentável do Brasil S.A. concessão de uso de bem público para exploração do potencial de energia hidráulica da UHE Jirau, de 12 de agosto de 2008, publicada no Diário Oficial da União de $13 / 8 / 2008$, apreciada formalmente pela Consultoria Jurídica por meio do Parecer Conjur/MME no 322/2008.

Da análise das manifestações jurídicas produzidas para a UHE Jirau, podem-se extrair trechos que revelam atenção a questões relativas ao impacto e à importância do empreendimento, ou seja, aspectos relativos ao mérito da política pública de geração de energia elétrica, para além do exame de aspectos de natureza formal, como a competência e a forma dos atos e procedimentos. A Nota Conjur/MME n ${ }^{\circ}$ 37/2008, por exemplo, consigna o seguinte:

$[\ldots]$

18. A grandiosidade, seja financeira, técnica ou estratégica, que envolve a implantação deste projeto, assim como a garantia de tarifas módicas e confiabilidade de fornecimento ao consumidor, requer por parte do governo precauções e condicionantes que justificam a exigência da formação de uma Sociedade de Propósito Específi- 
co pelo vencedor da licitação, preferencialmente sob a forma de Sociedade Anônima, um limite na composição acionária dos consórcios a serem compostos e o atendimento a alguns padrões de governança corporativa exigidos no Novo Mercado da Bolsa de Valores de São Paulo.

O Parecer Conjur/MME no 44/ 2008, por sua vez, ressalta:

\section{$[\ldots]$}

4. Fica caracterizada a importância e a prioridade das grandes Usinas Hidrelétricas da Amazônia para o atendimento ao Sistema Elétrico após 2011, em particular, as que já se dispõem de estudos de engenharia e ambientais desenvolvidos, de forma que possam ser consideradas para o atendimento ao mercado após aquele ano. As Usinas que se enquadram nesta situação são as de Jirau e Santo Antônio, no Rio Madeira, e Belo Monte, no Rio Xingu.

5. Dentro da ótica do planejamento e levando em consideração as incertezas no período, a decisão de implantar as Usinas de Jirau, Santo Antônio e Belo Monte, quase que simultaneamente, com seus cronogramas mínimos, é uma solução robusta, no que diz respeito à garantia do atendimento ao mercado, havendo inclusive a necessidade de incorporar simultaneamente outras usinas geradoras de menor porte para assegurar o pleno atendimento ao mercado, no período de 2011 a 2016.

Vale a referência, por derradeiro, à Nota Técnica Conjunta n ${ }^{\circ}$ 001/SEE-SPEASSEC-Conjur, que contou com a parti- cipação de advogada da União da Consultoria Jurídica do MME, elaborada com a finalidade de informar à Assessoria Parlamentar do Ministério o posicionamento das áreas técnicas e da Conjur sobre a conveniência e oportunidade de aprovação da Proposta de Fiscalização e Controle n ${ }^{\circ}$ 7/2008 da Comissão de Fiscalização Financeira e Controle da Câmara dos Deputados. Destacam-se: a elaboração conjunta por diversos órgãos do Ministério de Minas e Energia, entre eles a Consultoria Jurídica que, sendo órgão de execução da Advocacia-Geral da União, integra a estrutura organizacional do MME; a participação da Conjur-MME na elaboração de ato que, legalmente, não exige a obrigatória manifestação de órgão de assessoria jurídica; o detalhamento de questões técnicas e políticas, em abordagem multidisciplinar que ultrapassa o âmbito jurídico. Do mencionado trabalho, destaca-se trecho ilustrativo:

28. Uma vez demonstrada a possibilidade, inclusive com previsão explícita em Edital, de a ANEEL autorizar alterações nas características técnicas e no projeto base de aproveitamentos hidrelétricos licitados, bem como a conveniência em se adotar sempre a melhor solução técnica, ainda que ela seja proposta após a licitação, é preciso analisar a importância estratégica da UHE Jirau.

29. De fato, a simples dimensão da UHE Jirau com 3.300 MW de potência instalada e 1.975,30 MW médios de garantia física denota a importância singular desse projeto para a segurança do suprimento de energia elétrica ao mercado brasileiro e para a modicidade de preços e tarifas, visto 
que seu efeito sobre a definição do Custo Marginal de Operação (CMO) do sistema elétrico poderá ser percebido a partir do ano que vem.

É inequívoco, porém, que a análise documental não é suficiente para que se possa apreender o alcance da atuação da Consultoria Jurídica na modelagem da concessão da UHE Jirau, ao longo do desenvolvimento desse projeto, prestando consultoria e assessoramento jurídico ao ministro de Minas e Energia, à Secretaria Executiva, ao CNPE, à Assessoria Econômica e outras secretarias e departamentos diretamente envolvidos na concepção do empreendimento. A análise das manifestações jurídicas formais tem o condão de nos dar apenas uma ligeira noção do envolvimento desse órgão jurídico, não alcançando a participação em reuniões, audiências públicas, elaboração de atos legislativos e normativos, consultas informais, negociação política e arranjos de interesses econômicos, técnicos e ambientais, além da interface com a multidisciplinaridade de conhecimentos e áreas responsáveis por esta complexa operação, dentro e fora do Ministério.

Há, portanto, um longo caminho nesse estudo exploratório da atuação da Advocacia-Geral da União, sob o enfoque da efetividade das políticas públicas e dos projetos desenvolvidos pelo governo federal, restando inúmeras questões a serem investigadas, in loco, junto ao Ministério de Minas e Energia e, mais adiante, estendidas a outros ministérios e órgãos, tais como:

1. Na modelagem do leilão de compra de energia elétrica, nos projetos estruturantes e em outros, como vem-se dando a participação do órgão de consultoria e assessoramento jurídico? Quais as fases e os proce- dimentos que contam com a participação da Consultoria Jurídica do Ministério de Minas e Energia?

2. Há consultas informais, por e-mail, telefone ou pessoalmente, aos advogados da Consultoria Jurídica do Ministério de Minas e Energia?

3. As manifestações jurídicas exaradas pelo órgão de consultoria e assessoramento

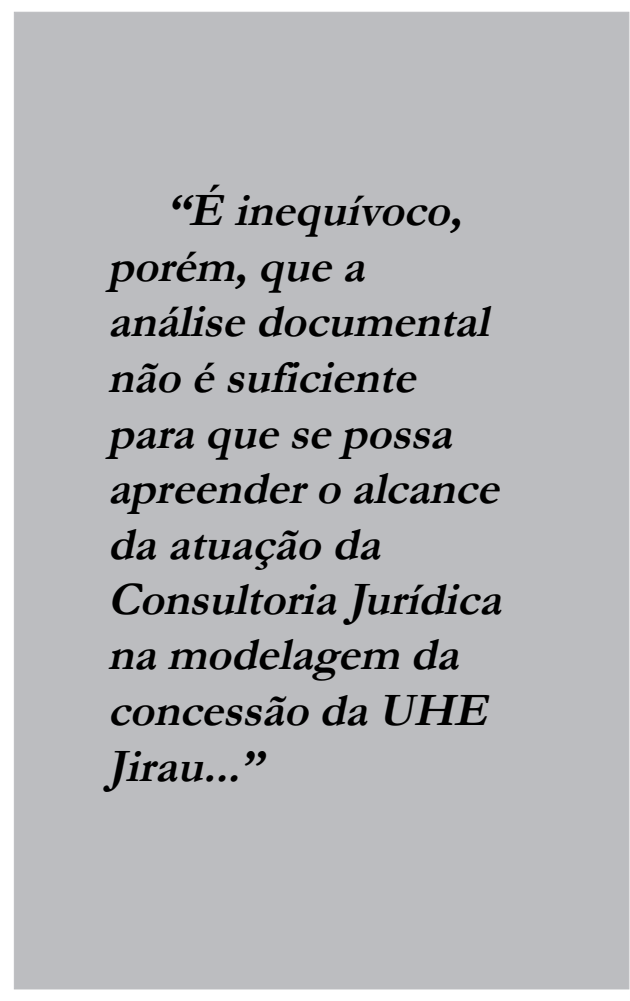

jurídico tratam, prevalentemente, de questões de natureza formal, como competência, forma dos atos, procedimento previsto em lei etc.? Ou os impactos e benefícios do projeto são avaliados também, ou seja, adentram em aspectos de mérito da política pública?

4. Quais as situações concretas em que a participação da Consultoria Jurídica foi além das hipóteses legais de obrigatoriedade do parecer jurídico prévio (tais 
como na análise de minutas de editais e contratos e dispensa de licitação)?

5. No caso da UHE de Jirau, a Comissão de Leilões propôs ao MME a alteração da data inicial prevista para o Leilão de Compra de Energia Elétrica Proveniente da Usina - de 9 de maio para 12 e depois 19 de maio de 2008, tendo a Assessoria Econômica do MME apontado as razões técnicas que recomendariam o adiamento proposto. Há registro de participação da Consultoria Jurídica nas tratativas informais prévias à formalização da decisão, em questões como essa?

6. A Consultoria Jurídica participa das reuniões prévias de discussão ou a rotina mais comum é de encaminhamento do processo, para análise formal e a posteriori dos atos normativos, editais, contratos e outras deliberações?

7. A Consultoria Jurídica acompanha as áreas técnicas e políticas às reuniões, sessões no Congresso Nacional e audiências públicas?

8. Os atos normativos (desde anteprojetos de leis a minutas de portarias e decretos) são elaborados em conjunto com a Consultoria Jurídica?

9. Há trânsito e diálogo das áreas técnicas com os advogados? Os advogados envolvem-se em discussões técnicas ou limitam-se estritamente à análise jurídica e constitucional?
10. Há outras características e perfis recomendáveis para melhor atuação da Consultoria Jurídica?

\section{Considerações finais}

Não há dúvida de que cabe ao órgão de consultoria e assessoramento da AGU manifestar-se sobre relevantes aspectos formais, cuja não observância pode gerar questionamentos judiciais, nulidade dos atos e comprometimento da política pública. $\mathrm{O}$ que se sustenta, porém, é que, para além de tais questões, a advocacia de Estado precisa estar atenta aos propósitos, resultados e impactos projetados pelo governo federal e envolver-se, efetivamente e eficazmente, na concepção do projeto, em toda sua extensão multidisciplinar e não jurídica. A produção e a interpretação do Direito, nessa linha, são colocadas como importante instrumental, em favor da consecução da política de governo, de acordo com os legítimos interesses políticos titularizados pelo governante eleito. Esse, parece-nos, é o caminho a ser trilhado pela Advocacia-Geral da União, atenta aos paradigmas de eficiência e efetividade do Estado e de sua burocracia, que se reformulam continuamente, para atender satisfatoriamente a sociedade e o cidadão.

(Artigo recebido em julho de 2010. Versão final em fevereiro de 2012).

\section{Notas}

${ }^{1} \mathrm{O}$ tema desenvolvido no presente artigo é objeto de dissertação de mestrado em Administração Pública, concluído pela autora no Instituto Universitário de Lisboa (ISCTE/IUL), em parceria com a Escola Brasileira de Administração Pública e de Empresas da Fundação Getúlio Vargas (Ebape/FGV). Registra-se que, sem a colaboração da Consultoria Jurídica do Ministério de Minas e Energia, a pesquisa não seria possível. 
${ }^{2}$ A Advocacia-Geral da União tem suas competências previstas no art. 131 da Constituição Federal e na Lei Complementar n. ${ }^{\circ}$ 73, de 10 de fevereiro de 1993.

${ }^{3}$ Para informações mais detalhadas sobre a indústria elétrica, com abordagem de aspectos técnicos, físicos e econômicos, consulte-se LOUREIRO, Luiz Gustavo Kaercher. Introdução ao regime jurídico da indústria elétrica: premissas gerais. Revista do Direito, Santa Cruz do Sul, v. 28, p. 143-191, 2008.

${ }^{4}[. .$.$] fixed spheres of competence, a defined hierarchy of offices; a clear distinction between public and$ private roles (and property) of the officials; specialization and expertise as the basis for action; full-time, career appointments for officials; e management by the application of a developing set of rules, knowledge of which was the special technical competence of the officials concerned.

${ }^{5}$ The traditional system of administration persisted for decades and on the whole was extremely successful. It fought several world wars, produced and administered a massive expansion of social programs, instituted largescale economic management for the public sector and initiated a host of remarkable policies. This system has now, however, gone from 'bubris for helplessness' (G. Dows and Larkey 1986). What happened to cause the largescale rethinking of governance that occurred during the 1980s and 1990s?

${ }^{6}$ Como corpo técnico que compõe as organizações governamentais.

${ }^{7}$ In short, bureacracy will continue to florish in the twenty-first century for many of the same reasons that it has flourished in the last century, it facilitates the governance process in ways that other organizational forms does not. Challenges to bureaucracy will always be challenges at the margin, moving tasks from a public sector bureaucracy to a private sector one, for example. Underneath these cosmetic responses to reforms, however, one will still see Weberian bureaucracies continue to perform a myriad of tasks.

${ }^{8} \mathrm{O}$ PDRAE diagnostica: "Por outro lado, o controle - a garantia do poder do Estado transforma-se na própria razão de ser do funcionário. Em conseqüência, o Estado volta-se para si mesmo, perdendo a noção de sua missão básica, que é servir à sociedade. A qualidade fundamental da administração pública burocrática é a efetividade no controle dos abusos; seu defeito, a ineficiência, a auto-referência, a incapacidade de voltar-se para o serviço aos cidadãos vistos como clientes. Este defeito, entretanto, não se revelou determinante na época do surgimento da administração pública burocrática porque os serviços do Estado eram muito reduzidos. O Estado limitava-se a manter a ordem e administrar a justiça, a garantir os contratos e a propriedade." (Mare, Pdrae, 1995, p. 15)

${ }^{9}[. .$.$] inadequacies in orientation which involve trained incapacity clearly derive from structural sources. The$ process may be briefly recapitulated. (1) An effective bureaucracy demands reliability of response and strict devotion to regulations. (2) Such devotion to the rules leads to their transformation into absolutes; they are no longer conceived as relative to a set of purposes. (3) This interferes with ready adaptation under special conditions not clearly envisaged by those who drew up the general rules. (4) Thus, the very elements which conduce toward efficiency in general produce inefficiency in specific instances. Full realization of the inadequacy is seldom attained by members of the group who have not divorced themselves from the meanings which the rules have for them. These rules in time become symbolic in cast, rather than strictly utilitarian.

${ }^{10}$ Complementando a ideia exposta por Rui Machete: "A preponderância de formalização, se aumentou a garantia dos cidadãos e o aperfeiçoamento do Estado de Direito, conduziu, em contrapartida, à segmentação das actividades e à sua excessiva autonomização em relação a acções complementares. Não raro há dactilógrafas capazes de escrever, mas não há máquinas ou vice-versa e, quando feitos os concursos, temos finalmente os funcionários, as máquinas já envelheceram. Os requisitos formais e probatórios requerem que o exercício do poder administrativo seja sempre documentado. O que não está escrito no processo não existe no mundo administrativo. As exigências de legalidade sobrelevam ao mérito da resolução cabal, atempada 
e eficaz das questões" (MACHETE, 1991). Ressalva-se, contudo, que notadamente a partir da entrada de Portugal na UE (em 1986), o país vem avançando muito na modernização de sua administração pública.

${ }^{11}$ Lei no 10.848, de 2004: “Art. 31. Fica revogado o art. $5^{\circ}$ da Lei no 9.648, de 27 de maio de 1998, assegurados os direitos constituídos durante sua vigência, em especial as atividades autorizadas em seus incisos II e IV. $\int 1^{\circ}$ Ficam excluídas do Programa Nacional de Desestatização (PND) a empresa Centrais Elétricas Brasileiras S/A (Eletrobrás) e suas controladas: Furnas Centrais Elétricas S/A, Companhia Hidro Elétrica do São Francisco (Chesf), Centrais Elétricas do Norte do Brasil S/A (Eletronorte) e Empresa Transmissora de Energia Elétrica do Sul do Brasil S/A (Eletrosul) e a Companhia de Geração Térmica de Energia Elétrica (CGTEE)".

${ }^{12}$ Informações extraídas da Lei no 10.848 , de 2004.

\section{Referências bibliográficas}

Brasil. Lei no 8.987, de 13 de fevereiro de 1995. Dispõe sobre o regime de concessão e permissão da prestação de serviços públicos previsto no art. 175 da Constituição Federal, e dá outras providências. Diário Oficial da União, Brasília, DF, 14 de fevereiro de 1995. Seção 1, p. 1917. Republicada no Diário Oficial da União, 28 de setembro de 1998.

Lei $\mathrm{n}^{\circ}$ 9.074, de 7 de julho de 1995. Estabelece normas para outorga e prorrogações das concessões e permissões de serviços públicos e dá outras providências. Diário Oficial da União, Brasília, DF, 8 de julho de 1995. Seção 1, p. 10125 (edição extra). Republicada no Diário Oficial da União, 28 de setembro de 1998.

. Lei n ${ }^{\circ}$ 9.427, de 26 de dezembro de 1996. Institui a Agência Nacional de Energia Elétrica - ANEEL, disciplina o regime das concessões de serviços públicos de energia elétrica e dá outras providências. Diário Oficial da União, Brasília, DF, 27 de dezembro de 1996. Seção 1, p. 28653. Republicada no Diário Oficial da União, 28 de setembro de 1998. Seção 1, p. 9.

Lei $\mathrm{n}^{\circ}$ 9.648, de 27 de maio de 1998. Altera dispositivos das Leis $\mathrm{n}^{\circ}$ 3.890-A, de 25 de abril de 1961, no 8.666, de 21 de junho de 1993, n 8.987, de 13 de fevereiro de 1995, n 9.074, de 7 de julho de 1995, no 9.427, de 26 de dezembro de 1996, e autoriza o Poder Executivo a promover a reestruturação da Centrais Elétricas Brasileiras - ELETROBRÁS e de suas subsidiárias e dá outras providências. Diário Oficial da União, Brasília, DF, 28 de maio de 1998. Seção 1, p. 1.

Lei no 10.847, de 15 de março de 2004. Autoriza a criação da Empresa de Pesquisa Energética - EPE e dá outras providências. Diário Oficial da União, Brasília, DF, 16 de março de 2004. Seção 1, p. 1.

. Lei no 10.848 , de 15 de março de 2004. Dispõe sobre a comercialização de energia elétrica, altera as Leis $\mathrm{n}^{\text {os }} 5.655$, de 20 de maio de 1971, 8.631, de 4 de março de 1993, 9.074, de 7 de julho de 1995, 9.427, de 26 de dezembro de 1996, 9.478, de 6 de agosto de 1997, 9.648, de 27 de maio de 1998, 9.991, de 24 de julho de 2000, 10.438, de 
26 de abril de 2002, e dá outras providências. Diário Oficial da União, Brasília, DF, 16 de março de 2004, Seção 1, p. 2.

Medida Provisória no 144 , de 10 de dezembro de 2003. Dispõe sobre a comercialização de energia elétrica, altera as Leis nos- 5.655, de 20 de maio de 1971, 8.631, de 4 de março de 1993, 9.074, de 7 de julho de 1995, 9.427, de 26 de dezembro de 1996, 9.478, de 6 de agosto de 1997, 9.648, de 27 de maio de 1998, 9.991, de 24 de julho de 2000, 10.438, de 26 de abril de 2002, e dá outras providências. Diário Oficial da União, Brasília, DF, 11 de dezembro de 2003. Seção 1, p. 1 - 4.

Portaria n $\mathrm{n}^{\mathrm{3}}$ 36, de 12 de fevereiro de 2008. Diário Oficial da União, Brasília, DF, 13 de fevereiro de 2008. Seção 1, p. 47.

Portaria no 114, de 20 de março de 2008. Diário Oficial da União, Brasília, DF, 24 de março de 2008. Seção 1, p. 81-2.

Resolução no 1 , de 11 de fevereiro de 2008. Indica a Usina Hidrelétrica denominada UHE Jirau, localizada no Rio Madeira, no Estado de Rondônia, como projeto de geração com prioridade de licitação, e dá outras providências. Diário Oficial da União, Brasília, DF, 15 de fevereiro de 2008. Seção 1, p. 49.

Correia , Tiago B.; Melo, Elbia; Costa , Agnes M.; Silva, Adriano J. Trajetória das reformas institucionais da indústria elétrica brasileira e novas perspectivas de mercado. Revista Economia, v. 7, n. 3, set./dez. 2006.

Costa, Frederico Lustosa da. História das reformas administrativas no Brasil: narrativas, teorizações e representações. Revista do Serviço Público, ENAP, Brasília, v. 59, n. 3, jul./ set. 2008.

Derlien, Hans-Ulrich. Genesis and structure of evaluation efforts in comparative perspective. In: RIST, Ray C. (Ed.). Program Evaluation and the Management of Government: patterns and prospects across eight nations. New Brunswick; Londres: Transaction Publishers, 1990.

Empresa de Pesquisa Energética (EPE). Plano Decenal de Expansão de Energia - PDE2019. Brasília, 2009. Disponível em: <www.epe.gov.br>. Acesso em: 29 jun. 2010.

Gomes, João A. Salis. A perspectiva jurídica na avaliação de políticas públicas. In: ENcontro Ina: A Avaliação na Administração Pública, 1., 1998, Oeiras. Acta Geral. Oeiras: INA, 23-24 mar. 1998.

Loureiro, Luiz Gustavo Kaercher. Introdução ao regime jurídico da indústria elétrica: premissas gerais. Revista do Direito, Santa Cruz do Sul, v. 28, p. 143-191, 2008.

Machete, Rui. Estudos de direito público e ciência política. Porto: Fundação Oliveira Martins, 1991.

Majone, Giandomenico. Do estado positivo ao estado regulador: causas e conseqüências de mudanças no modo de governança. Tradução René Loncan. Revista do Serviço Público, ENAP, Brasília, ano 50, v. 1, jan./mar. 1999.

MeIER, Kenneth J.; HiLl, Gregory C. Bureaucracy in the twenty-firt century, In: FerLIE, Ewan; Lynn JR., Laurence E.; PollitT, Christopher. The Oxford Handbook of Public Management. Oxford: Oxford University Press, 2005.

Merton, Robert K. Social Theory and Social Structure. New York: Free Press, 1968. 
Ministério da Administração Federal e Reforma do Estado (Mare). Plano Diretor da Reforma do Aparelho do Estado. Brasília: Imprensa Nacional, 1995.

Peters, B. Guy. The Future of the Governing: four emerging models. Studies in Government and Public Policy. Lawrence: University Press of Kansas, 1996.

Poldit, Christopher; Bouckaert, Geert. Public Management Reform: a comparative analysis. 2. ed. Oxford: Oxford University Press, 2004.

Suleiman, Ezra N. Dismantling Democratic States. Princeton: Princeton University Press, 2003.

VAsConcelos, Flávio Carvalho. Racionalidade, autoridade e burocracia: as bases da definição de um tipo organizacional pós-burocrático. Revista de Administração Pública, FGV, Rio de Janeiro, v. 38, n. 2, mar./abr. 2004. 


\section{Resumo - Resumen - Abstract}

\section{Reflexões sobre a atuação da Advocacia-Geral da União em projetos de geração de energia hidrelétrica}

Tania Patricia de Lara Vaq

O presente trabalho contém algumas reflexões sobre o papel da advocacia de Estado, na qual está inserida a Advocacia-Geral da União e seus membros de carreira, no desenvolvimento e na implementação de políticas públicas e projetos do governo federal brasileiro, especificamente sob o enfoque da gestão pública e dos movimentos de modernização do Estado e reformulação do modelo burocrático. Com foco na fase de modelagem do leilão para compra de energia elétrica proveniente da Usina Hidrelétrica de Jirau, licitada de acordo com o novo modelo do setor elétrico, examina-se a atuação do órgão de consultoria e assessoramento jurídico do Ministério de Minas e Energia e o papel que desempenha.

Palavras-chaves: disfunções burocráticas, Advocacia-Geral da União, setor elétrico.

\section{Reflexiones sobre la actuación de la Abogacía General de la Unión en proyectos de generación de energía hidroeléctrica}

Tania Patricia de Lara Var.

Este trabajo contiene algunas reflexiones sobre el rol de la abogacía de Estado, en la cual está insertada la Abogacía General de la Unión y sus miembros de carrera, en el desarrollo e implementación de políticas públicas y proyectos del Gobierno Federal brasileño, específicamente bajo el enfoque de la gestión pública y de los movimientos de modernización del Estado y reformulación del modelo burocrático. Con enfoque en la etapa de modelado de la subasta para compra de energía eléctrica proveniente de la Planta Hidroeléctrica de Jirau, licitada de acuerdo con el nuevo modelo del sector eléctrico, se examina la actuación del organismo de consultoría y asesoramiento legal del Ministerio de Minas y Energía y el rol que desempeña.

Palabras claves: disfunciones burocráticas, Abogacía General de la Unión, sector eléctrico.

\section{Reflections on the role of the Attorney General's Office in hydropower generation projects \\ Tania Patricia de Lara Vaz}

This paper contains some reflections on the role of State advocacy, which comprises the Attorney General's Office and its career members, in developing and implementing public policies and projects by the Brazilian Federal Government, particularly under the focus of public management and of movement for state modernization and reform of the bureaucratic model. With a focus on the modeling phase of the auction to purchase electric power from the hydroelectric plant Jirau, bided according to the new model of the electric sector, it examines the role of the legal consultancy and assistance body of the Ministry of Mines and Energy.

Keywords: bureaucratic dysfunctions, Attorney General's Office, electric power sector.

\section{Tania Patricia de Lara Vaz}

Mestre em Administração Pública pelo Instituto Universitário de Lisboa (ISCTE-IUL), em parceria com a Ebape/FGV.É Advogada da União e Diretora de Gestão Estratégica da Advocacia-Geral da União.

Contato:tania.vaz@agu.gov.br. 